Article

\title{
A Tapered Capillary-Based Contactless Atmospheric Pressure Ionization Mass Spectrometry for On-Line Preconcentration and Separation of Small Organics
}

\author{
Yen-Chun Chen ${ }^{1,2,+}$, Arun Krishnamurthy ${ }^{1,2,+}$, Szu-Hua Chen ${ }^{1,2}$ and Yu-Chie Chen $1,2, *$ (D) \\ 1 Department of Applied Chemistry, National Yang Ming Chiao Tung University, Hsinchu 300, Taiwan; \\ pattytjp@gmail.com (Y.-C.C.); aknm11@gmail.com (A.K.); ritachen02112814@gmail.com (S.-H.C.) \\ 2 Department of Applied Chemistry, National Chiao Tung University, Hsinchu 300, Taiwan \\ * Correspondence: yuchie@nctu.edu.tw; Tel.: +886-3-5131527; Fax: +886-3-5723764 \\ + These authors contributed equally to this work.
}

check for updates

Citation: Chen, Y.-C.;

Krishnamurthy, A.; Chen, S.-H.; Chen,

Y.-C. A Tapered Capillary-Based

Contactless Atmospheric Pressure

Ionization Mass Spectrometry for

On-Line Preconcentration and

Separation of Small Organics.

Separations 2021, 8, 111. https://

doi.org/10.3390/separations 8080111

Academic Editor: Victoria Samanidou

Received: 24 June 2021

Accepted: 26 July 2021

Published: 29 July 2021

Publisher's Note: MDPI stays neutral with regard to jurisdictional claims in published maps and institutional affiliations.

Copyright: (c) 2021 by the authors. Licensee MDPI, Basel, Switzerland. This article is an open access article distributed under the terms and conditions of the Creative Commons Attribution (CC BY) license (https:/ / creativecommons.org/licenses/by/ $4.0 /)$.

\begin{abstract}
Capillary electrophoresis (CE) is an effective technique for the separation of different analytes. Moreover, online preconcentration of trace analytes in the capillary for $\mathrm{CE}$ analysis has been demonstrated. CE and capillary electrochromatography (CEC) are suitable for the separation of analytes with similar polarities. Given that CE and CEC are only used to separate small-volume samples, sensitive mass spectrometry (MS) is a suitable detection tool for CE and CEC. Contactless atmospheric pressure ionization (C-API) is a continuous flow ion source that only uses a short capillary as the ionization emitter operated at atmospheric pressure for MS analysis. In this study, we demonstrated the feasibility of hyphenating CE/CEC with C-API-MS by using a short and tapered capillary as the interface. The short capillary (a few centimeters) can function as the separation/preconcentration tube and the ionization emitter. This hyphenated technique can be used to analyze small organics within a few minutes. The suitability of using the hyphenated technique for online preconcentration, separation, and quantitative analysis for small organics is demonstrated in this study.
\end{abstract}

Keywords: contactless-atmospheric pressure ionization (C-API); mass spectrometry; capillary electrophoresis (CE); capillary electrochromatography (CEC); preconcentration

\section{Introduction}

Remarkable progress has been achieved in exploring ambient ionization techniques for mass spectrometry (MS) in the past two decades [1-7]. The simplicity and minimization of sample preparation are unique features of these developed techniques [6,7]. Reducing/minimizing sample preparation steps can significantly reduce analysis time, but ion suppression effects $[8,9]$ caused by nontarget ions in complex samples may obscure the target ion peaks with low concentrations and poor ionization efficiency. Conventionally, liquid separation techniques can be coupled online with MS using atmospheric pressure ionization (API) methods [10], including electrospray ionization (ESI) and atmospheric pressure chemical ionization as the interface. Owing to a similar flow rate to API, capillarybased separation techniques such as capillary electrophoresis (CE) [11-13] and capillary electrochromatography (CEC) [14] have been coupled with MS without considerable compromise. A wall coating or stationary packing capillary is used as a channel for conducting CEC [14]. Moreover, the preconcentration of analytes in the capillary has been extensively studied by using different sample stacking approaches for CE analysis [15-19]. Conventional API techniques, such as ESI, have been used as the ionization method to couple online with these capillary-based techniques with MS [20-24]. In some of these approaches, liquid and gas sheaths are required to couple CE with ESI-MS [20-22]. When coupling most of the recently developed ambient ionization methods with liquid separation techniques, such as $\mathrm{CE}$, direct coupling may not be feasible. Nevertheless, few reports have demonstrated 
the feasibility of coupling CE with ambient ionization MS [25-27]. In addition, if online preconcentration, such as sample stacking in $\mathrm{CE}$, can be carried out for low-concentration analytes followed by online detection of MS, then the sample pretreatment and analysis time can be substantially reduced.

An ionization method called contactless atmospheric pressure ionization (C-API) [28-31] is a continuous flow ion source, which uses a tapered capillary as the sampling tube and the ionization emitter. Owing to capillary action, sample solution can be continuously directed from the capillary inlet immersed in a microliter-sized droplet to the tapered end that is placed close to $(\sim 0.5 \mathrm{~mm})$ the inlet of the mass spectrometer applied with a high voltage (e.g., $\pm 4.5 \mathrm{kV}$ ) [28-31]. Fine charged droplets eluted from the capillary outlet readily form gas-phased ions [28-31]. Although no direct electric contact is made on the capillary outlet, the electric field provided by the inlet of the mass spectrometer is sufficient to induce the charge accumulation of the eluent on the capillary outlet to generate electrospray. Moreover, capillary action ensures continuous flow of the sample solution to the capillary outlet and facilitates the stabilization of ion signals.

Given that a short and tapered capillary is used as the sampling tube and the ionization emitter in C-API, the combination of the capillary-based separation/preconcentration techniques with C-API is possible. A short and tapered capillary can be used as an interface to couple capillary-based separation/preconcentration system with C-API-MS without requiring any additional accessories. Without applying any additional electric contact on the capillary, the electric field provided by the inlet of the mass spectrometer was expected to be sufficient for direct separation/preconcentration to occur in the capillary. We herein demonstrate the feasibility of using a short and tapered capillary as the interface to couple CE/CEC and sample stacking in CE online with C-API-MS without requiring any additional interfacing components.

\section{Experimental}

The details of reagents, materials, and instrumentation are described in Supporting Information.

\subsection{Preparation of Tapered Capillaries}

The capillary was placed vertically using a metal stand, whereas its lower end was clamped by an object with a weight of $50 \mathrm{~g}$. The capillary was heated at its lower end using a butane torch to draw a narrow tip. The tapered capillary with a given length was cut using a ceramic cutter. The tapered end of the resultant capillary was dipped into aqueous HF $(24 \%, v / v)$ for $20 \mathrm{~min}$, followed by rinse with deionized water. HF is a hazardous acid and should be handled with care. Figure S1 shows the resultant tapered capillary. The as-prepared capillary was thoroughly dried in an oven to remove water prior to experiments. The tapered end of these capillaries was fragile and should be handled with care.

\subsection{Capillary-Based On-Line Concentration Combined with C-API-MS Analysis}

When conducting online concentration of analytes, the capillary (ID: $50 \mu \mathrm{m}$; OD: $365 \mu \mathrm{m}$ ) was flushed with aqueous sodium hydroxide $(1 \mathrm{~N})$ for $1 \mathrm{~h}$, deionized water again for $1 \mathrm{~h}$, and the solvent containing acetonitrile and deionized water $(3: 2, v / v)$ for another $1 \mathrm{~h}$. The capillary was tapered based on the procedures described above. The tapered capillary was cut according to the required length used for the stacking experiments. Ammonium bicarbonate and ammonium acetate buffers $(10 \mathrm{mM})$, which were used as leading and terminating buffers for in-capillary preconcentration experiments, were initially prepared in deionized water followed by 10-fold dilution with acetonitrile/deionized water $(2: 1, v / v)$. The tapered capillary $(\sim 6.8 \mathrm{~cm})$ was then placed in front of the inlet of the mass spectrometer with a distance of $\sim 0.5 \mathrm{~mm}$ and filled with ammonium bicarbonate buffer at $\mathrm{pH} 11$, which had been 10-fold diluted by acetonitrile/deionized water (2:1, $v / v)$, by immersing the capillary inlet to a droplet $(10 \mu \mathrm{L})$ containing the buffer for $2 \mathrm{~min}$ based on capillary action. Subsequently, the capillary inlet was immersed into a sample droplet $(10 \mu \mathrm{L})$ for $3 \mathrm{~min}$ 
followed by immersing in a droplet containing ammonium acetate buffer (1 mM, pH 5), which had been 10 -fold diluted by acetonitrile/deionized water $(2: 1, v / v)$, by moving the metal plate to the sample or buffer droplet. Model samples including lysine and histidine were prepared in deionized water initially. Prior to analysis, the model samples were then 10-fold diluted by the solvent containing acetonitrile and deionized water $(3: 2, v / v)$. After the analytes appeared in the electropherogram and completed the analysis, the capillary was flushed by immersing its inlet in the solvent containing acetonitrile and deionized water $(3: 2, v / v)$ for 30 min to ensure all the residues were removed. The sample, buffer, and running solvent were introduced to the capillary based on capillary action.

\subsection{Quantitative Analysis of Histidine in Aqueous Samples}

We prepared a model sample containing histidine $(50 \mu \mathrm{M})$ spiked with creatinine $(1 \mathrm{mM})$ as the internal standard in deionized water. The standard addition method was used to determine the concentration of histidine in the sample. The as-prepared sample was 100 -fold diluted prior to analysis. Histidine standards with different concentrations $(0.28,0.43,0.65,0.97,1.45,2.18$, and $3.27 \mu \mathrm{M})$ were spiked to the 100 -fold-diluted sample prior to online preconcentration followed by C-API-MS analysis using a short capillary (length: $\sim 6.8 \mathrm{~cm}$ ) as the interface. Three replicates were conducted. The calibration curve was plotted by plotting the ratio of the intensity of the peak derived from histidine to that of the peak derived from creatinine versus the concentration of spiked histidine. The intercept cross the $X$ axis was obtained. The experimental concentration of histidine in the sample was estimated by multiplying 100 by the intercept of the $X$ axis.

\subsection{Setup of C-API-Based Separation and MS Analysis}

A tapered capillary coated with trichloro(octadecyl)silane $\left(\mathrm{C}_{18}\right)$ with a given length was placed vertically in front of the orifice of the mass spectrometer. The details of the wall coating of the capillary are described in Supporting Information. The voltage applied on the inlet of the mass spectrometer was $-4.5 \mathrm{kV}$. An aluminum metal plate $(10 \mathrm{~cm} \times 10 \mathrm{~cm})$ used for the deposition of samples and running solvents was placed on a screw-driven adjustable stand in front of the mass spectrometer. The tapered capillary was placed orthogonally to the metal plate and its inlet was immersed in the running solvent deposited on the metal plate by adjusting the screw-driven stand. The solvent through the capillary from the capillary inlet in the solvent droplet could reach the outlet of the capillary owing to capillary action. The capillary was conditioned by the running solvent that was used for separation for $30 \mathrm{~min}$ prior to injection of the sample. When injecting samples, the metal plate was moved to the droplet containing the sample $(\sim 10 \mu \mathrm{L})$ for a given time (e.g., $2 \mathrm{~s})$ to introduce the sample into the capillary inlet. The metal plate was then moved back to the droplet containing the running solvent. Mass spectra were acquired by the mass spectrometer during the infusion of samples and solvents.

\subsection{Separation of Small Organics in a $C_{18}$-Wall Coated Capillary On-Line Combined with C-API MS}

Five organics including arginine, atrazine, ametryn, prometryn, and adenosine were selected as model samples for conducting separation in a $\mathrm{C}_{18}$-wall coated capillary (length: $\sim 3.5 \mathrm{~cm}$ ). Running solvents were prepared by mixing acetonitrile and water with different ratios. The mixtures of analytes were prepared by mixing an equal concentration $(50 \mu \mathrm{M}, 20 \mu \mathrm{L})$ of analytes. Prior to introduction to the capillary, the analytes were 10-fold diluted by acetonitrile/deionized water $(1: 4, v / v)$. The final concentration of each analyte in the mixture was $1 \mu \mathrm{M}$. The capillary was filled with the running solvent, initially followed by immersing the capillary inlet in a sample droplet $(10 \mu \mathrm{L})$ for $2 \mathrm{~s}$ and then a droplet containing the running solvent. The mass spectrometer was switched on to acquire the mass spectra when introducing the sample and running solvent to the capillary. 


\section{Results and Discussion}

When stacking a large volume of analytes with a low concentration in a capillary, a certain electrical field is applied to the two ends of the capillary and a sample zone containing trace analytes in the capillary can be concentrated between leading and terminating buffer zones with high and low ion motilities, respectively [14-17]. In general, a long capillary is required to fill a sufficiently long sample zone in the capillary for stacking target analytes into a narrow window for detection. Nevertheless, we demonstrated that a short capillary $(\mathrm{few} \mathrm{cm}$ ) can be used to concentrate trace analytes in a short capillary followed by online detection by C-API-MS. Figure 1 shows the typical setup of our approach. A short and tapered capillary held by a pair of tweezers was placed vertically in front $(\sim 0.5 \mathrm{~mm})$ of the mass spectrometer. The inlet of the mass spectrometer was applied with a voltage of $-4.5 \mathrm{kV}$ when the positive ion mode was conducted. No direct electric contact was made on the C-API capillary. Liquid droplets $(5-10 \mu \mathrm{L})$ containing samples and solvents were placed on the aluminum plate $(10 \mathrm{~cm} \times 10 \mathrm{~cm})$. The short capillary was filled with the solvent by immersing its inlet into the solvent droplet. When introducing the sample, the metal plate was moved to the sample droplet, in which the sample can be continuously introduced into the capillary based on capillary action.

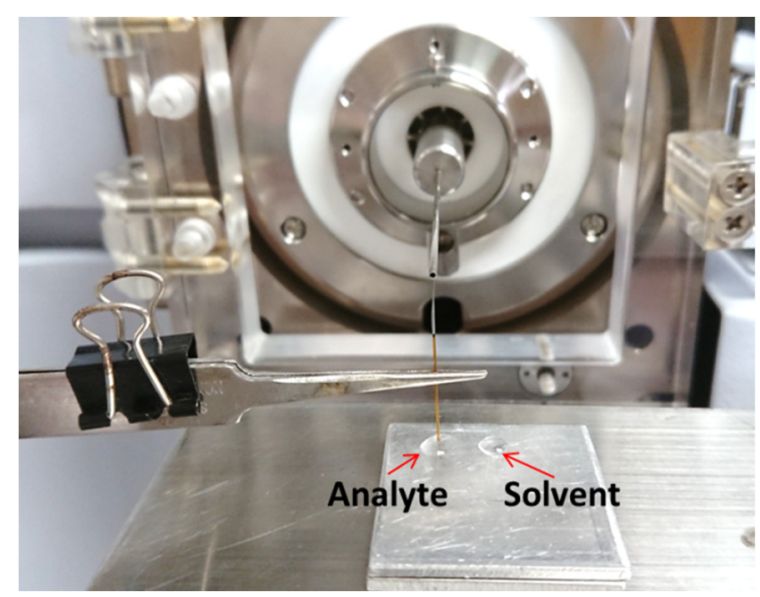

Figure 1. Photograph of the hyphenated technique using a short and tapered capillary as the separation/concentration channel and the ionization emitter.

We initially used histidine $\left(5 \mathrm{nM}, \mathrm{MH}^{+}=156.07\right)$ as the model sample to demonstrate the feasibility of using the current setup to preconcentrate and detect the sample online using C-PAI-MS. Histidine was prepared in deionized water initially. Prior to analysis, the model samples were 10-fold diluted by the solvent containing acetonitrile and deionized water $(2: 1, v / v)$. Leading $(\mathrm{pH} 11)$ and terminating buffers $(\mathrm{pH} 5)$ were used to stack the model sample in the capillary. Ammonium bicarbonate and ammonium acetate buffers used as leading and terminating buffers, respectively, were initially prepared in deionized water followed by 10-fold dilution with the solvent containing acetonitrile/deionized water $(2: 1, v / v)$. When conducting the in-capillary preconcentration experiment, the mass spectrometer was switched on in the beginning when the leading buffer was introduced to the capillary. Specifically, a tapered capillary (length: $\sim 6.8 \mathrm{~cm}$; tip diameter: $\sim 14 \mu \mathrm{m}$ ) was filled with ammonium bicarbonate buffer ( $1 \mathrm{mM}, \mathrm{pH} 11)$ for $2 \mathrm{~min}$. The sample solution was introduced for $3 \mathrm{~min}$ based on capillary action by immersing the capillary inlet to the sample droplet. The capillary was moved to the droplet containing ammonium acetate buffer ( $1 \mathrm{mM}, \mathrm{pH} 5)$, and the buffer was continuously infused into the capillary based on capillary action. Figure 2a,b show the extracted ion chromatograms (EICs) at $\mathrm{m} / \mathrm{z} 156.07$ obtained before and after in-capillary preconcentration, respectively. Figure $2 \mathrm{c}, \mathrm{d}$ show the corresponding mass spectra. The peak resulting from protonated histidine was only observed after sample stacking (Figure $2 \mathrm{~b}, \mathrm{~d}$ ). The peak at $m / z 149.02$ was derived from the solvent background. In addition, lysine was further used as the model sample to 
demonstrate the feasibility of using the current approach for online preconcentration and detection by C-API-MS. Figure 2e,f show the EICs at $m / z 147.11$ obtained before and after online preconcentration by $\mathrm{pH}$ junction stacking, respectively. Figure $2 \mathrm{~g}, \mathrm{~h}$ show the corresponding mass spectra. Similar to the results obtained when histidine was used as the model sample, the peak resulting from protonated lysine only appeared after preconcentration. These results indicate that conducting online preconcentration and detection of amino acids using a short capillary as the preconcentration tube and ionization emitter is possible for C-API-MS analysis.

(a)

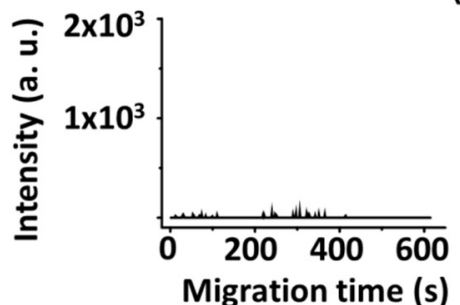

(c)

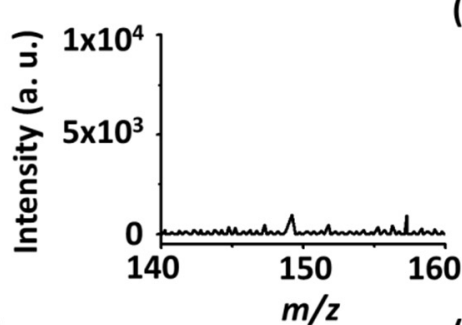

(e)

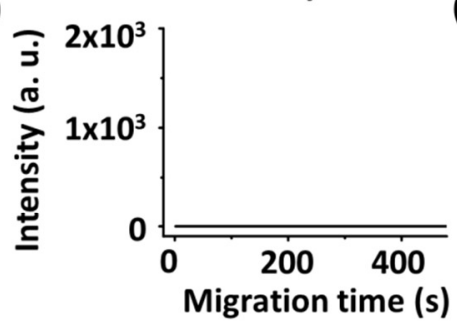

(g)

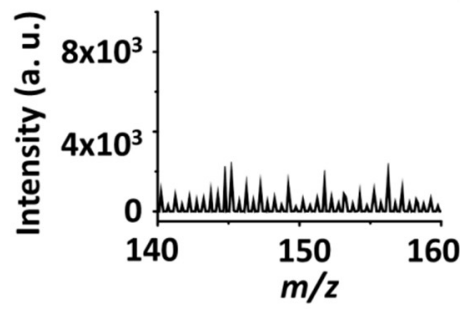

(b)

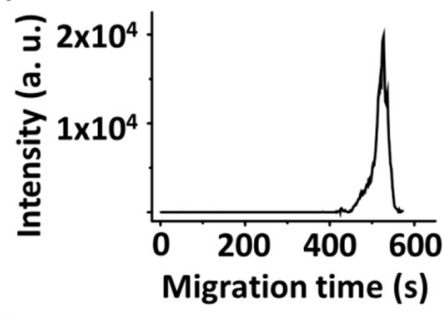

(d)

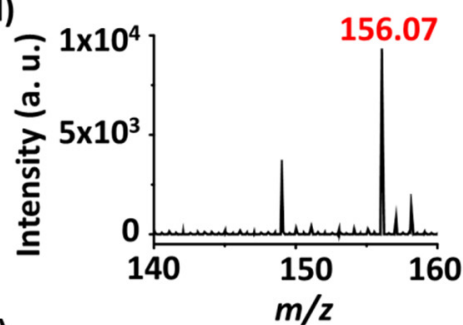

(f)

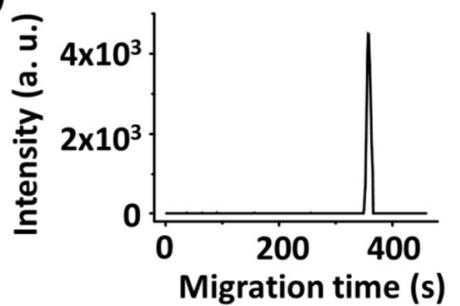

(h)

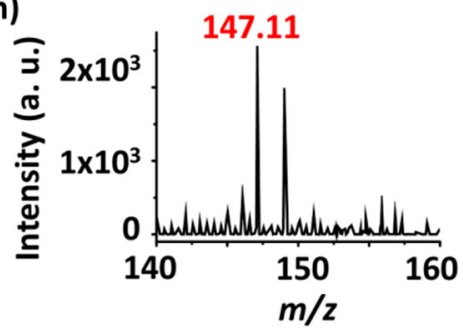

Figure 2. Coupling on-capillary preconcentration with C-API-MS analysis. A tapered capillary (length: $\sim 6.8 \mathrm{cml}$; OD: $\sim 14 \mu \mathrm{m}$ ) was used as the interface. Extracted ion chromatogram (EIC) at $m / z 156.07$ (histidine $\left.(5 \mathrm{nM}),[\mathrm{M}+\mathrm{H}]^{+}\right)$obtained from (a) direct C-API-MS analysis and (b) after on-line preconcentration followed by C-API-MS analysis. (c,d) The corresponding mass spectra. EIC at $m / z 147.11$ (lysine $(25 \mathrm{nM}),[\mathrm{M}+\mathrm{H}]^{+}$) obtained from (e) direct C-API-MS analysis and (f) after on-line preconcentration followed by C-API-MS analysis. (g,h) The corresponding mass spectra. Mass tolerance was set to $\pm 0.01 \mathrm{amu}$.

Amino acids, such as histidine, can be found in urine with a concentration range of 17-90 $\mu \mathrm{M}$ [32]. To further demonstrate the feasibility of using our approach for the analysis of endogenous histidine, we prepared a simulated sample by spiking histidine $(50 \mu \mathrm{M})$ and creatinine $(1 \mathrm{mM})$ in deionized water. The standard addition method was used to determine the concentration of histidine in the sample. The mixture as mentioned above was 100 -fold diluted prior to analysis. Different concentrations of histidine standards 
$(0.28,0.43,0.65,0.97,1.45,2.18$, and $3.27 \mu \mathrm{M})$ were spiked to the 100 -fold-diluted sample prior to online preconcentration followed by C-API-MS analysis using a short capillary (length: $\sim 6.8 \mathrm{~cm}$ ) as the interface. The experimental steps were the same as those used to obtain Figure 2. Figure 3 shows the resultant mass spectra of the samples. The peaks appearing at $m / z 114.07$ (red dot), 136.04 (blue dot), and 152.02 (green dots) were derived from protonated creatinine, sodium, and potassium adducts of creatinine, respectively. The peak at $m / z 156.07$ (yellow dot), corresponding to protonated histidine, was observed in the mass spectrum before addition of additional histidine (Figure 3a). Moreover, the ion intensity of the protonated histidine increased with increasing concentration of the spiked histidine (yellow dots, Figure 3b-h). Figure 3i shows the resultant calibration curve by plotting the ion intensity of the protonated histidine to the sum of the ion intensity derived from creatinine versus the concentration of spiked histidine. According to the resultant equation $\left(y=0.1597 x+0.0785, R^{2}=0.9961\right)$, the intercept on the $x$ axis was -0.4915 . That is, $\sim 0.4915 \mu \mathrm{M}$ histidine existed in the 100-fold-diluted sample according to the results obtained by standard addition. The concentration of histidine in the sample was $\sim 49 \mu \mathrm{M}$, which was $\sim 2 \%$ off from the true concentration of histidine in the prepared sample. These results suggest the feasibility of using the current approach for quantitative analysis.
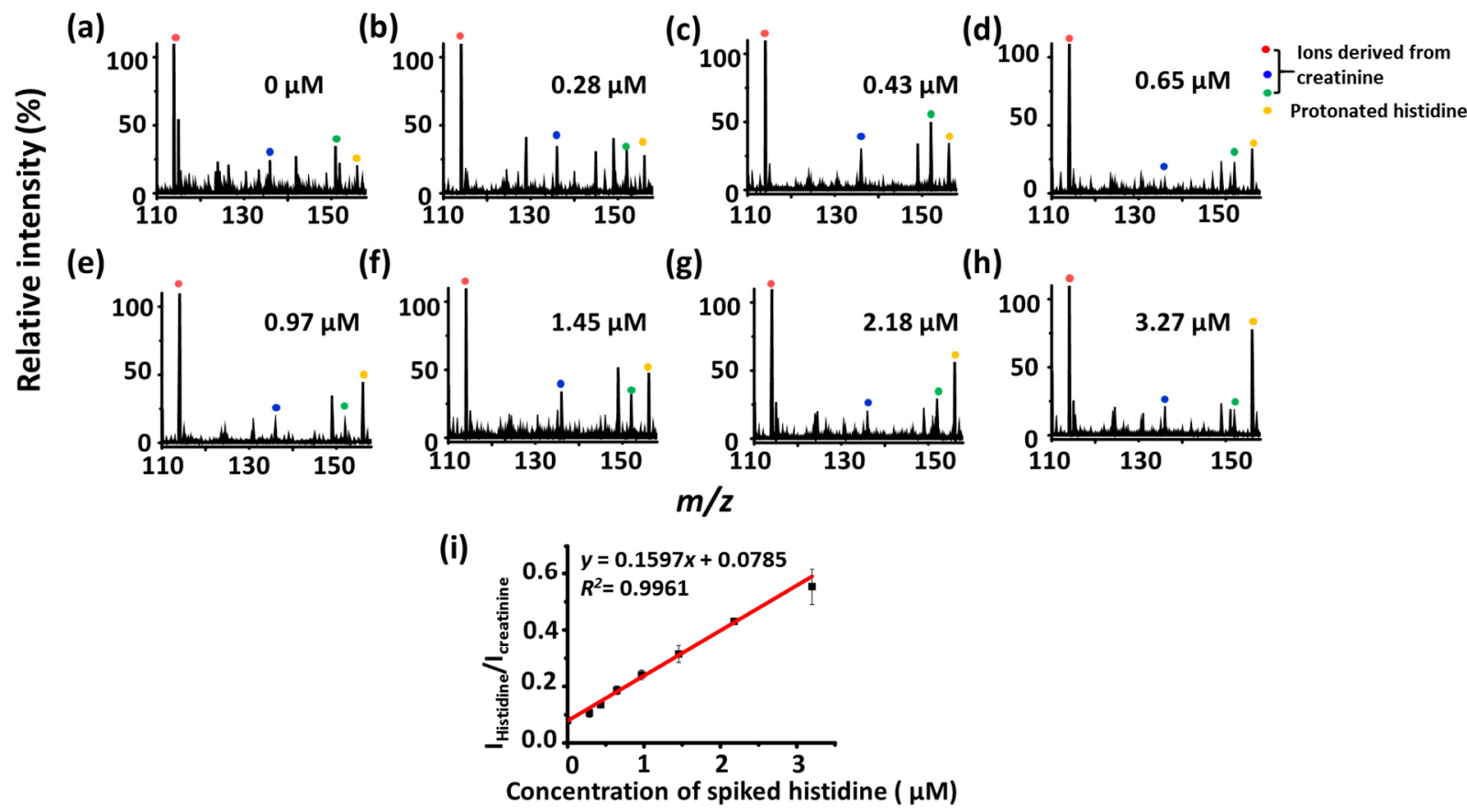

Figure 3. On-line preconcentration of histidine from a 100 -fold diluted sample that originally contained histidine $(50 \mu \mathrm{M})$ and creatinine $(1 \mathrm{mM})$ combined with the standard addition method for quantitative determination of histidine. (a-h) Representative mass spectra of the samples obtained from on-line preconcentration of histidine from aqueous samples spiked with histidine. The creatinine ion peaks $\left.\left.\left.m / z 114.07[\mathrm{M}+\mathrm{H}]^{+}\right), 136.04\left([\mathrm{M}+\mathrm{Na}]^{+}\right), 152.02[\mathrm{M}+\mathrm{K}]^{+}\right)\right)$in the samples were used as internal standard. (i) Plot of the ratio of the ion intensity of the peak at $m / z 156.07\left(I_{\text {his }}\right.$, histidine, $\left.\left.[\mathrm{M}+\mathrm{H}]^{+}\right)\right)$to the sum $\left(I_{c r e}\right)$ of the ions derived from creatinine versus the concentration of spiked histidine. Mass tolerance was set to \pm 0.01 amu.

In addition, we coated the wall of the C-API capillary with $\mathrm{C}_{18}$ [33] to conduct CEC online with C-API-MS analysis. The details of the $\mathrm{C}_{18}$ modification and fabrication of the capillary are described in the Supporting Information. The $\mathrm{C}_{18}$-modified capillary $(\sim 3.5 \mathrm{~cm})$ was used as the separation column and ionization emitter in combining CEC and C-API-MS. We applied $-4.50 \mathrm{kV}$ on the inlet of the mass spectrometer. The solvents consisting of acetonitrile and deionized water with different ratios were used as the mobile phase. The mixture containing arginine, atrazine, prometryn, ametryn, and adenosine with different hydrophobicity was used as the model sample. The hydrophobicity of these analytes varied, and the order of hydrophobicity from low to high is as follows: arginine 
$\left(\log K_{o w}=-4.79\right)$ [34], adenosine $\left(\log K_{o w}=-1.12\right)$ [35], atrazine $\left(\log K_{o w}=+2.60\right)$ [36], ametryn $\left(\log K_{o w}=+3.07\right)$ [36], and prometryn $\left(\log K_{o w}=+3.40\right)$ [36]. $K_{o w}$ is the concentration of solute in octanol phase/the concentration in water phase. Figure $4 \mathrm{a}-\mathrm{d}$ present the resultant EICs at $m / z 175$ (arginine, black curve), 216 (atrazine, red curve), 228 (ametryn, blue curve), 242 (prometryn, green curve), and 268 (adenosine, pink curve) derived from the mixture by using acetonitrile and deionized water with different volume ratios of $8 / 2,6 / 4,3 / 7$, and $2 / 8$, respectively, as the mobile phase. No considerable improvement was observed in the separation between arginine (black curve) and the four other analytes when the mobile phase containing acetonitrile and deionized water with the ratios $(v / v)$ of $8 / 2$ (Figure 4a) and $6 / 4$ (Figure $4 \mathrm{~b}$ ) were used in the separation. When the acetonitrile-to-deionized water ratio was changed to $3 / 7$, the separation was improved (Figure $4 \mathrm{c}$ ). Five peaks resulting from the five model analytes can be separated. When the acetonitrile-to-deionized water ratio was adjusted to $2 / 8$, the separation among analyte peaks was further improved (Figure 4d). The order of the elution time of these analytes followed the presented order of their hydrophobic properties. Specifically, arginine with a relatively low hydrophobicity was eluted first. Subsequently, adenosine (pink curve), atrazine (red curve), ametryn (blue curve), and prometryn (green curve) were eluted in sequence. The total analysis time for the separation of these five model analytes was $2 \mathrm{~min}$. Furthermore, triazine molecules, namely, atrazine, ametryn, and prometryn, with similar chemical structures can be separated in this short C-API capillary. These results indicate that conducting fast separation in the C-API capillary for analytes with similar chemical structures is feasible using the online C-API-MS approach. The setup is remarkably simple, and the analysis time is relatively short.

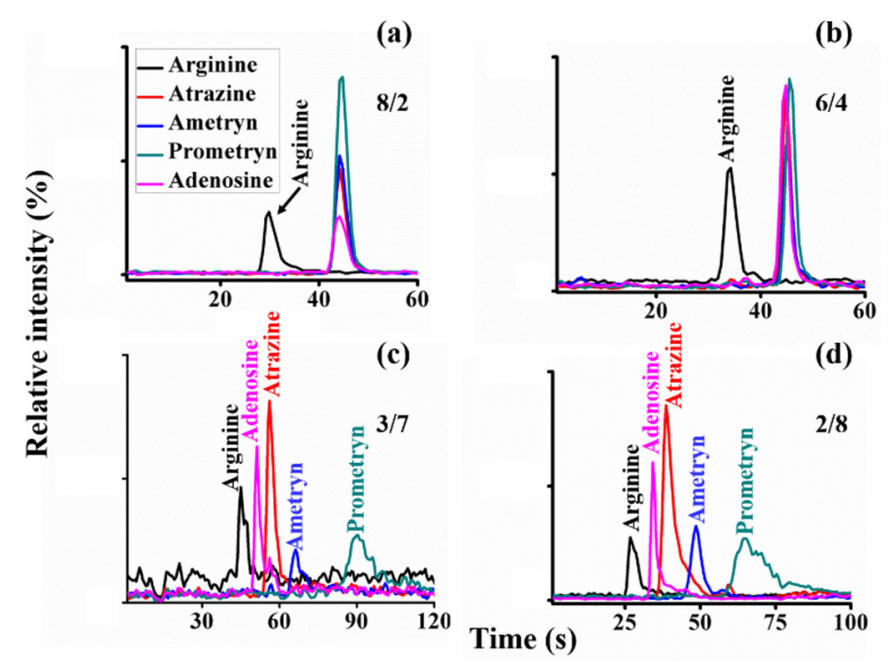

Figure 4. Separation of 5 organics $(100 \mathrm{nM})$ on a C18 wall-coated capillary and on-line for C-API-MS analysis. EICs at $m / z 175$ (arginine, black curve), 216 (atrazine, red curve), 228 (ametryn, blue curve), 242 (prometryn, green curve), and 268 (adenosine, pink curve) by using acetonitrile/water with different volume ratios: (a) 8:2, (b) 6:4, (c) 3:7, and (d) 2:8 as the running buffer in C18 modified fused silica capillary (length: $\sim 3.5 \mathrm{~cm}$ ). The voltage applied on the inlet of the mass spectrometer was $-4.5 \mathrm{kV}$.

We further examined whether the developed hyphenated technique is suitable for quantitative analysis. Ametryn $\left([\mathrm{M}+\mathrm{H}]^{+}=228\right)$ was selected as the target analyte, and arginine $\left([\mathrm{M}+\mathrm{H}]^{+}=175\right)$ was used as the internal standard. Figure 5 a illustrates the plot of the ratio of the intensity integrated area of the ion at $m / z 228$ to the ion at $m / z 175$ from their corresponding EICs versus the concentration $(0.23-6.00 \mu \mathrm{M})$ of ametryn. The ratio increased with the increasing concentration of ametryn. The linear dynamic range was $0.23-1.78 \mu \mathrm{M}$ $\left(y=1.2896 x-0.049, R^{2}=0.9971\right)$ (Figure $\left.5 b\right)$. Figure $5 c$ shows the corresponding EICs at $\mathrm{m} / \mathrm{z} 228$ (ametryn, red curve) and 175 (arginine, blue curve) obtained from the samples 
containing ametryn within the linear dynamic range $(0.23-1.78 \mu \mathrm{M})$. These results indicate that the current approach is suitable for conducting quantitative analysis.

\section{(a)}

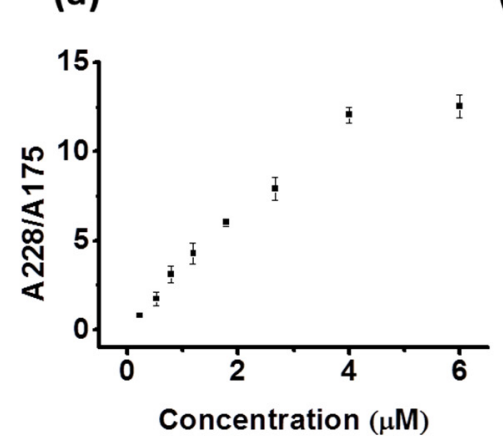

(b)

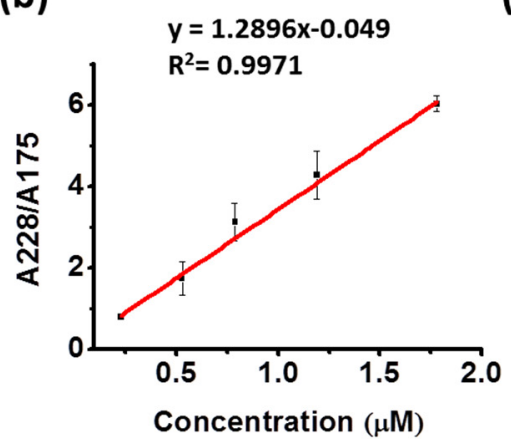

(c)

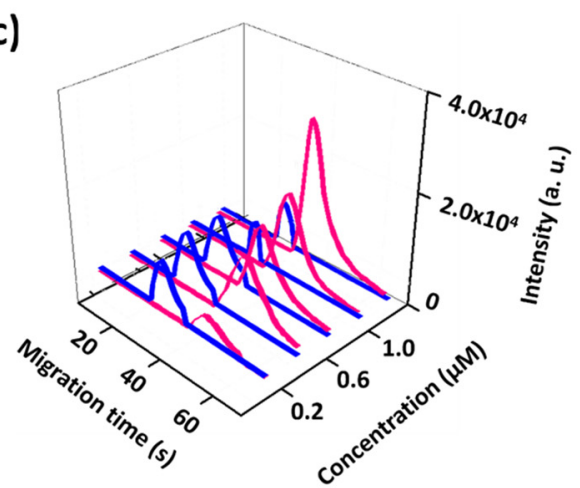

Figure 5. Quantitative analysis. (a) Plot obtained by plotting the ratio integrated intensity area of the ion peak from corresponding EICs at $m / z 228$ (ametryn) to the ion peak at $m / z 175$ (arginine) versus the concentration of ametryn. The samples contained ametryn with different concentrations $(0.2-6 \mu \mathrm{M})$ spiked with arginine $(1.5 \mu \mathrm{M})$. Three replicates were conducted for each concentration. The voltage applied on the inlet of the mass spectrometer was $-4.5 \mathrm{kV}$, while the length of the tapered capillary was $\sim 2.5 \mathrm{~cm}$. The running solvent was composed of acetonitrile/deionized water $(2: 8, v / v)$. (b) Plot of the linear dynamic range $(0.23-1.78 \mu \mathrm{M}$ ) derived from Panel (a). (c) Representative EICs at $m / z 175$ (blue) and 228 (pink) used to plot Panel (b).

\section{Conclusions}

We have successfully demonstrated a hyphenated technique by combining capillarybased preconcentration/separation techniques with the flow ion source, C-API, using a short and tapered capillary as the interface. The C-API capillary not only works as the sampling tube and ionization emitter, but it can also be used as an on-line concentration and a separation channel. Although no direct electric contact was made on the C-API capillary, analyte preconcentration and CEC-like separation can be conducted in an unmodified and a C18-modified capillary, respectively. The voltage applied on the inlet of the mass spectrometer provides driving force to transport the solvent (mobile phase) from the capillary inlet to the outlet in addition to the driving force resulting from the capillary action. The voltage causes separation and facilitates the ionization of analytes eluted on the capillary. Given that the C-API capillary is considerably short $(\sim 3.5 \mathrm{~cm})$, five analytes can be separated for $1.5 \mathrm{~min}$. This study is the first one to report that an open-air source also functions as a separation/preconcentration tool. A short capillary is inexpensive, but it can be used as a multifunctional tool in the current approach. The advantages of this approach include fast separation, simplicity, and low cost. This work may possess significant potential in the miniaturization of separation techniques for combination with MS.

Supplementary Materials: The following are available online at https:/ / www.mdpi.com/article/ 10.3390/separations8080111/s1, Additional experimental details, Figure S1: Photograph of the as-prepared capillary with a tapered end.

Author Contributions: Conceptualization, Y.-C.C. (Yen-Chun Chen), A.K., S.-H.C. and Y.-C.C. (YuChie Chen); methodology, Y.-C.C. (Yen-Chun Chen), A.K., S.-H.C.; validation, Y.-C.C. (Yen-Chun Chen), A.K., S.-H.C. and Y.-C.C. (Yu-Chie Chen); investigation, Y.-C.C. (Yu-Chie Chen), A.K., S.-H.C.; resources, Y.-C.C. (Yen-Chun Chen); writing-original draft preparation, Y.-C.C. (Yen-Chun Chen), A.K., Y.-C.C. (Yu-Chie Chen); supervision, Y.-C.C. (Yu-Chie Chen); project administration, Y.-C.C. (Yu-Chie Chen); funding acquisition, Y.-C.C. (Yu-Chie Chen). All authors have read and agreed to the published version of the manuscript.

Funding: This research was funded by Ministry of Science and Technology of Taiwan (MOST 1052113-M-009-022-MY3 and MOST 108-2113-M-009-018-MY3). 
Acknowledgments: We thank the Ministry of Science and Technology of Taiwan (MOST 105-2113M-009-022-MY3; MOST 108-2113-M-009-018-MY3) for financial support of this research. AK thanks NCTU for providing him International Student Scholarship.

Conflicts of Interest: The authors declare no conflict of interest.

\section{References}

1. Javanshada, R.; Venter, A.R. Ambient ionization mass spectrometry: Real-time, proximal sample processing and ionization. Anal. Methods 2017, 9, 4896-4907. [CrossRef]

2. Meher, A.K.; Chen, Y.-C. Electrospray modifications for advancing mass spectrometric analysis. Mass Spectrom. 2017, 6, S0057S0057. [CrossRef]

3. Lebedev, A.T. Ambient ionization mass spectrometry. Russ. Chem. Rev. 2015, 84, 665-692. [CrossRef]

4. Kandiah, M.; Urban, P.L. Advances in ultrasensitive mass spectrometry of organic molecules. Chem. Soc. Rev. 2013, 42, 5299-5322. [CrossRef] [PubMed]

5. Chen, Y.-C.; Urban, P.L. Time-resolved mass spectrometry. TrAC Trends Anal. Chem. 2013, 44, 106-120. [CrossRef]

6. Monge, M.E.; Harris, G.A.; Dwivedi, P.; Fernández, F.M. Mass spectrometry: Recent advances in direct open air surface sampling/iIonization. Chem. Rev. 2013, 113, 2269-2308. [CrossRef]

7. Cooks, R.G.; Ouyang, Z.; Takats, Z.; Wiseman, J.M. Detection technologies. Ambient mass spectrometry. Science 2006, 311, 1566-1570. [CrossRef] [PubMed]

8. Annesley, T.M. Ion suppression in mass spectrometry. Clin. Chem. 2003, 49, 1041-1044. [CrossRef]

9. Wang, Z.; Zhu, H.; Huang, G. Ion suppress ion effect in desorption electrospray ionization and electrospray ionization mass spectrometry. Rapid Commun. Mass Spectrom. 2017, 31, 1957-1962. [CrossRef] [PubMed]

10. Niessen, W.M.A. State-of-the-art in liquid chromatography-mass spectrometry. J. Chromatogr. A 1999, 856, 179-197. [CrossRef]

11. Niessen, W.M.A.; Tjaden, U.R.; Van der Greef, J. Capillary electrophoresis mass spectrometry. J. Chromatogr. A 1993, 636, 3-19. [CrossRef]

12. Harstad, R.K.; Johnson, A.C.; Weisenberger, M.M.; Bowser, M.T. Capillary electrophoresis. Anal. Chem. 2016, 88, 299-319. [CrossRef]

13. Ramos-Payán, M.; Ocaña-Gonzalez, J.A.; Fernández-Torres, R.M.; Llobera, A.; Bello-López, M.Á. Recent trends in capillary electrophoresis for complex samples analysis: A review. Electrophoresis 2018, 39, 111-125. [CrossRef] [PubMed]

14. Cikalo, M.G.; Bartle, K.D.; Robson, M.; Myers, P.; Euerby, M.R. Capillary electrochromatography. Tutorial review. Analyst 1998, 123, 87R-102R. [CrossRef]

15. Slampova, A.; Mala, Z.; Gebauer, P.; Bocek, P. Recent progress of sample stacking in capillary electrophoresis (2014-2016). Electrophoresis 2017, 38, 20-32. [CrossRef]

16. Burgi, D.S.; Chien, R.L. Optimization in samples stacking for high-performance capillary electrophoresis. Anal. Chem. 1991, 63, 2042-2047. [CrossRef]

17. Simpson, S.L.; Quirino, J.P.; Terabe, S. On-line sample preconcentration in capillary electrophoresis Fundamentals and applications. J. Chromatogr. A 2008, 1184, 504-541. [CrossRef] [PubMed]

18. Britz-McKibbin, P.; Bebault, G.M.; Chen, D.D.Y. Velocity-difference induced focusing of nucleotides in capillary electrophoresis with a dynamic pH junction. Anal. Chem. 2000, 72, 1729-1735. [CrossRef] [PubMed]

19. Thompson, T.J.; Foret, F.; Vouros, P.; Karger, B.L. Capillary electrophoresis/electrospray ionization mass spectrometry: Improvement of protein detection limits using on-column transient isotachophoretic sample preconcentration. Anal. Chem. 1993, 65, 900-906. [CrossRef]

20. Cai, J.; Henion, J. Capillary electrophoresis-mass spectrometry. J. Chromatogr. A 1995, 703, 667-692. [CrossRef]

21. Moini, M. Capillary electrophoresis mass spectrometry and its application to the analysis of biological mixtures. Anal. Bioanal. Chem. 2002, 373, 466-480. [CrossRef]

22. Simpson, D.C.; Smith, R.D. Combining capillary electrophoresis with mass spectrometry for applications in proteomics. Electrophoresis 2005, 26, 1291-1305. [CrossRef] [PubMed]

23. Lu, G.; Crihfield, C.L.; Srikanth, G.; Veltri, L.M.; Holland, L.A. Capillary electrophoresis separations of glycans. Chem. Rev. 2018, 118, 7867-7885. [CrossRef]

24. Mischak, H.; Coon, J.J.; Novak, J.; Weissinger, E.M.; Schanstra, J.P.; Dominiczak, A.F. Capillary electrophoresis-mass spectrometry as a powerful tool in biomarker discovery and clinical diagnosis: An update of recent developments. Mass Spectrom. Rev. 2009, 28, 703-724. [CrossRef] [PubMed]

25. Wu, Y.-T.; Chen, Y.-C. Sheathless capillary electrophoresis/electrospray ionization mass spectrometry using a pulled bare fused-silica capillary as the electrospray emitter. Anal. Chem. 2005, 77, 2071-2077. [CrossRef] [PubMed]

26. Zhang, Y.; Ai, W.; Bai, Y.; Zhou, Y.; Wen, L.; Zhang, X.; Liu, H. An interface for online coupling capillary electrophoresis to dielectric barrier discharge ionization mass spectrometry. Anal. Bioanal. Chem. 2016, 408, 8655-8661. [CrossRef]

27. Park, S.-G.; Murray, K.K. Ambient laser ablation sampling for capillary electrophoresis mass spectrometry. Rapid Commun. Mass Spectrom. 2013, 27, 1673-1680. [CrossRef] [PubMed]

28. Chang, C.; Xu, G.; Bai, Y.; Zhang, C.; Li, X.; Li, M.; Liu, Y.; Liu, H. Online coupling of capillary electrophoresis with direct analysis in real time mass spectrometry. Anal. Chem. 2013, 85, 170-176. [CrossRef] 
29. Hsieh, C.-H.; Chang, C.-H.; Urban, P.L.; Chen, Y.-C. Capillary action-supported contactless atmospheric pressure ionization for the combined sampling and mass spectrometric analysis of biomolecules. Anal. Chem. 2011, 83, 2866-2869. [CrossRef]

30. Hsieh, C.-H.; Chao, C.-S.; Mong, K.-K.; Chen, Y.-C. Study of salt effects in ultrasonication-assisted spray ionization mass spectrometry. J. Mass Spectrom. 2012, 47, 480-483.

31. Hsieh, C.-H.; Meher, A.K.; Chen, Y.-C. Automatic sampling and analysis of organics and biomolecules by capillary actionsupported contactless atmospheric pressure ionization mass spectrometry. PLoS ONE 2013, 8, e66292. [CrossRef]

32. Bouatra, S.; Aziat, F.; Mandal, R.; Guo, A.C.; Wilson, M.R.; Knox, C.; Bjorndahl, T.C.; Krishnamurthy, R.; Saleem, F.; Liu, P.; et al. The human urine metabolome. PLoS ONE 2013, 8, e73076. [CrossRef] [PubMed]

33. Takeuchi, T.; Matsuoka, K.; Watanabe, Y.; Ishii, D. Studies of open-tubular micro-capillary liquid chromatography: II. Chemically bonded octadecylsilane stationary phase. J. Chromatogr. 1978, 158, 227-232.

34. Yannai, S. Dictionary of Food Compounds with CD-ROM: Additives, Flavors, and Ingredients; CRC Press: New York, NY, USA, 2003.

35. Machatha, S.G.; Yalkowsky, S.H. Comparison of the octanol/water partition coefficients calculated by $\mathrm{Clog}{ }^{\circledR}, \mathrm{ACDlogP}$ and KowWin ${ }^{\circledR}$ to experimentally determined values. Int. J. Pharm. 2005, 294, 185-192. [CrossRef] [PubMed]

36. Dauwe, C.; Sellergren, B. Influence of template basicity and hydrophobicity on the molecular recognition properties of molecularly imprinted polymers. J. Chromatogr. A 1996, 753, 191-200. [CrossRef] 